\title{
Publicaciones en China y en Taiwán de las traducciones de las novelas españolas al chino
}

\author{
MENGHSUAN Ku \\ Universidad Nacional de Chengchi \\ elenaku@nccu.edu.tw
}

Recibido: 3 de diciembre de 2011

Aceptado: 27 de febrero de 2012

\section{RESUMEN}

Durante la última década, ha habido un progreso considerable en cuanto a las publicaciones de traducciones literarias al chino, especialmente del género novelístico. Este hecho nos motiva a estudiar el fenómeno de las novelas españolas peninsulares traducidas al chino. Para comenzar este trabajo, hemos trazado un panorama general de las publicaciones de los temas relacionados con el español y España en China, Taiwán, Hong Kong y Macao. Aplicamos la propuesta del mecenazgo de Lefevere (1992/ 2004), el factor esencial que diferencia la industria de la publicación en China y Taiwán. En cuanto a los aspectos que hemos corroborado en nuestro trabajo, destacan las estrategias de las publicaciones, los contenidos de las novelas seleccionadas y los intercambios de patentes de las traducciones.

Palabras clave: traducción literaria, novelas españolas, China, Taiwán, Hong Kong.

Chinese translations of Spanish novels in China and in Taiwan

\begin{abstract}
In the last decade, there has been a considerable progress as far as Spanish publications of literary translations into Chinese, especially the genre: novels. This fact motivates us to study where and how peninsular Spanish novels have been translated into Chinese. IN the first part of the article, we start by describing the phenomena of publications of the Spanish translations in China, Taiwan, Hong Kong, and Macao. Lefevere's concept of "patronage" (1992/2004) was borrowed to distinguish China from Taiwan. The, other issues covered in our article include the analysis of strategies of publication, the contents of selected novels and the exchanges of translation rights.
\end{abstract}


Keywords: literary translation, Spanish novels, China, Taiwan, Hong Kong.

Sumario: 1. Introducción. 2. Principales publicaciones de las traducciones de las obras españolas en el mundo chino. 2.1. China: el cambio hacia las traducciones del castellano peninsular. 2.2. Taiwán: publicaciones ambiciosas de traducciones del castellano. 2.3. Hong Kong: formación de la traducción enfocada en inglés-chino. 2.4. Macao: libros del castellano publicados en China y en Taiwán. 3. Factores del mecenazgo en las traducciones. 3.1. Influencias de factores del mecenazgo. 3.2. Tendencia de las publicaciones temáticas en China. 3.3. Publicaciones por autores en Taiwán. 3.4. Factores económicos que contribuyen a las colaboraciones. 4. Conclusiones. Referencias bibliográficas.

\section{Introducción}

Si observamos las publicaciones de las novelas españolas en chino, podemos destacar un progreso notable durante los últimos años. Aparte de los libros más populares de tipo comercial, auto-ayuda o aprendizaje de inglés, las novelas españolas ocupan ya un rincón en las librerías. Los lectores descubren que en la mayor cadena de librerías de Taiwán, Eslite (言戒爿), se encuentran las novelas traducidas en la sección de novedades, así como de vez en cuando aparecen en la lista de las mejores novelas extranjeras vendidas. En Beijing, en el edificio de libros de Zhongguancun ( Fl鼎村村), las series de traducciones de novelas españolas en las estanterías de la literatura extranjera también han llamado nuestra atención. Este fenómeno nos motiva a estudiar la situación actual de la publicación de los temas relacionados con España y el español en el mundo chino, especialmente en lo que a las traducciones de las novelas españolas se refiere, así como un contraste de las tendencias estratégicas de las editoriales en diferentes países.

A diferencia de Tendencias del mercado taiwanés en la traducción al chino de novelas contemporáneas en español (Ku, 2010: 183-204), cuyo enfoque se sitúa en el mercado de Taiwán con corpus tanto de España como de América en una investigación basada en el estudio de las profesiones de los traductores que realizan las traducciones y los diversos orígenes de las traducciones aparte de los textos originales del castellano, el presente estudio se centra en las novelas españolas y en sus respectivas traducciones al chino producidas en China, Taiwán, Hong Kong y Macao, en un trabajo comparativo entre países en el que el factor del mecenazgo juega un papel crucial. En el apartado siguiente, haremos una presentación general de la industria editorial y de publicación de los libros relacionados con el español en China, Taiwán, Hong Kong y Macao, cuatro regiones de habla china que cuentan con la mayor industria de publicaciones de Asia, con el objetivo de localizar las áreas con mayores libros españoles publicados entre ellos. Más adelante, en el tercer apartado, delimitamos el estudio a China y Taiwán, dos países cuya lengua oficial es el chino y poseen la mayor parte de las publicaciones de novelas españolas traducidas al chino, para indagar en las influencias y en las estrategias de las editoriales en estos dos países desde la perspectiva del mecenazgo. 


\section{Principales publicaciones de las traducciones de las obras españolas en el mundo chino}

Aunque hay publicaciones del chino en varios continentes, incluso en América y en Europa, en diferentes formatos, como prensa o libro, las mayores editoriales de los libros en chino se encuentran en $\mathrm{Asia}^{1}$. En este sentido, China, Taiwán y Hong Kong son las tres bases de las publicaciones en chino a nivel internacional (Xin 2010: 21); se encargan de la tarea de la publicación de las obras en chino o traducidas al chino en el mundo. Así pues, dedicamos este apartado a la presentación del contexto social, la posibilidad y la actualidad de la publicación de los libros relacionados con el español y especialmente con la literatura española traducida al chino publicada en China, Taiwán y Hong Kong. Incluimos en el último subapartado las publicaciones en Macao debido a su similitud con Hong Kong, ya que ambos territorios fueron colonizados por potencias occidentales y recibieron una gran influencia de la cultura occidental y una creciente internacionalización.

\subsection{China: el cambio hacia las traducciones del castellano peninsular}

Hacia finales del siglo XX, la didáctica del español y las traducciones de las obras del castellano ya estaban bastante desarrolladas en China, sobre todo a partir de 2006 con la apertura en Beijing del Instituto Cervantes, lo que permitió una mayor difusión del castellano en ese país. Aún así, el español sigue siendo en China todavía una lengua minoritaria si lo comparamos con otras lenguas más populares en el país asiático como el inglés o el japonés. Podemos afirmar, pues, que el uso del español es bastante limitado en China. Por tanto, los alumnos de los departamentos de español de las universidades chinas más famosas, como la Universidad de Estudios Extranjeros de Beijing, no pueden compararse con los departamentos de lenguas más demandadas. La población que se dedica a las lenguas minoritarias o con menor difusión en China se refleja directamente en la cantidad y en la variedad de las obras traducidas. Actualmente, entre los libros traducidos, todavía no hay muchos traducidos del español al chino.

La Biblioteca del Instituto Cervantes de Beijing tiene por nombre el del poeta Antonio Machado. Cuenta con gran cantidad de libros y es una de las mayores bibliotecas asiáticas con más libros en castellano y en la que pueden encontrarse muchos libros que han dejado de publicarse. Según el Instituto Cervantes, la Biblioteca Antonio Machado tiene unos siete mil títulos de libros y datos. Por lo tanto, esta biblioteca tiene un valor y una contribución muy importante a la hora de conservar los libros relacionados con el español y de ofrecer preciadas informaciones para las investigaciones de

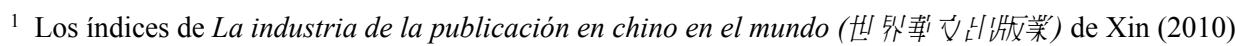
incluyen las publicaciones en chino en China, Taiwán, Hong Kong, Macao, Singapur, Malasia, Norte América, Europa, etc. Los lugares del mayor porcentaje son países asiáticos: China 76\%, Taiwán 17\%, Hong Kong $6 \%$, otros $1 \%$. 
traducción de textos castellanos al chino. Si observamos su catálogo, vemos que sobre los años 90 del siglo anterior comenzaron a realizarse paulatinamente traducciones al chino de textos en español procedentes tanto de España como de Latinoamérica. Sin embargo, después de este siglo, las traducciones en chino son principalmente de autores españoles, argentinos, mexicanos y chilenos. Por otro lado, aunque son traducciones de esta última década, los autores no siempre se limitan a los contemporáneos. Muchas obras clásicas como Don Quijote de la Mancha o Don Juan Tenorio pueden encontrarse traducidas al chino en nuestros días. Una mayor cantidad de obras de autores españoles que de obras hispanoamericanas revelan la tendencia de los últimos años.

\subsection{Taiwán: publicaciones ambiciosas de traducciones del castellano}

La industria editorial en Taiwán siempre ha sido variada y libre, aunque las obras publicadas son principalmente de autores anglosajones, se ven poco las obras de autores europeos, por no hablar de las de escritores hispanoamericanos. Sin embargo, a partir del año 2000, las obras traducidas de los autores españoles empiezan a ocupar un rincón en las librerías de Taiwán. En 2001, 2003 incluso hasta 2004, la cantidad publicada es poco relevante: Sitak (并代) publicó la traducción de El club

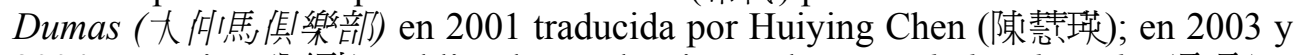
2004, Eurasian (卧神) publicó las traducciones de Las edades de Lulu (露霜) y

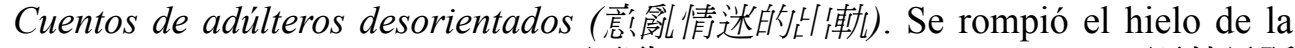

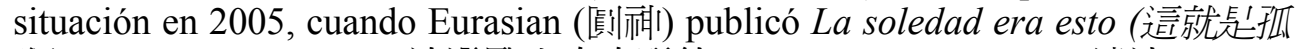

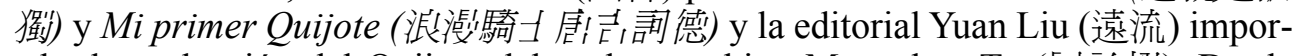

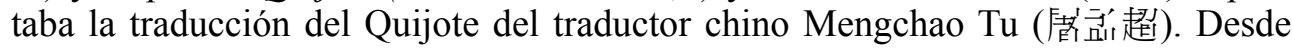
entonces, la visibilidad de las traducciones de las obras de autores españoles es más notable y en 2008 se encuentran más de 10 traducciones en un solo año.

Las traducciones con un plan estratégico para su publicación es una de las características del mercado de las traducciones del castellano, como el proyecto de la casa Eurasian, que ha fundado una base firme de la cultura de la literatura peninsular en el mercado taiwanés. Durante los últimos diez años, entre las editoriales que introducen autores hispanoamericanos contamos entre otras con Eurasian (卧新!), Azoth

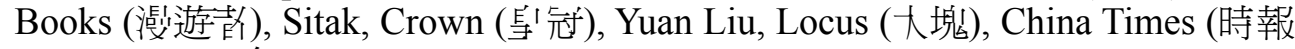
) y Rye Field ( $\mathrm{K}_{\mathrm{y}} \mathrm{F}^{\prime}$ '). Entre estas editoriales, Eurasian tiene una cantidad considerable de novelas, aunque Azoth Books tiene a escritores de gran renombre. Del análisis de la situación actual de las traducciones de obras españolas en el mercado taiwanés se puede extraer la conclusión de que hay una creciente ambición en presentar más autores españoles a los lectores taiwaneses.

\subsection{Hong Kong: formación de la traducción enfocada en inglés-chino}

A finales de julio de 2010, la exposición de libros organizada por el Trade Development Council de Hong Kong cumplió 21 años. Se vendieron más de cuarenta mil entradas los días de la exposición. Si consideramos su locación geográfica y el con- 
texto histórico, Hong Kong es el mejor lugar para la exportación e importación. Por tanto, según los datos del mismo Trade Development Council, en 2006 Hong Kong se ha convertido en el tercer suministrador de libros y prensa. En los últimos años la industria editorial de Hong Kong está cada vez más comercializada, la cantidad aumenta progresivamente año tras año y revela el éxito de esta industria en el mercado y la posibilidad de internacionalización. La Asociación de Publicación fundada en 1988 se dedica a desarrollar y elevar el nivel de las editoriales hongkongnesas y ha contribuido bastante en cuanto a la industria editorial se refiere. Si bien, debido a la historia de la colonia británica, los negocios de libros de lenguas extranjeras son principalmente del inglés y se encuentran pocas obras escritas en otras lenguas europeas.

La experiencia en la formación de traductores e intérpretes de Hongkong es insuperable debido a su ambiente multicultural y multilingüe. Por ejemplo, el uso mezclado del cantonés y el inglés en la vida cotidiana de sus habitantes es un hecho muy común. La Universidad de Chino de Hong Kong logró la primera promoción de traducción asiática en 1994 y en 2002 el máster de traducción informática. En cuanto al programa universitario, la misma universidad tiene el Departmento de Chino, Traducción y Lingüística. El esfuerzo dedicado a la formación de la traducción es continuo, así como la programación de cursos, lo que refleja totalmente las necesidades del mercado de la traducción en Hong Kong. Sin embargo, el chino y el inglés son las dos lenguas principales de traducción, aunque la Universidad de Chino ofrece la enseñanza de otras lenguas como el japonés y el coreano. Incluso en el Departamento de Inglés hay clases de español, limitado por las especialidades de la lengua. Sólo hay traducción entre el inglés y el español en clase y aún no hay clases de traducción entre el chino y el español. La formación del castellano afecta directamente la operación del mercado y las editoriales hongkonesas no publican traducciones de novelas españolas. En las bibliotecas o en el mercado encontramos traducciones en chino de obras españolas publicadas en China o en Taiwán pero no en Hong Kong.

\subsection{Macao: libros del castellano publicados en China y en Taiwán}

Debido a su historia y geografía, Macao tiene una situación similar a la de Hong Kong, ya que también cuenta con un ambiente multilingüe. Actualmente, las dos universidades más representativas son la Universidad de Macao y el Instituto Politécnico de Macao (澳門). Aquella es la primera universidad moderna de Macao, en cuyo Departamento de Inglés de la Facultad de Letras hay un programa de traducción universitario y un posgrado. En cuanto al programa de los estudios de traducción, hay requisitos de lenguas como el chino, el portugués y el inglés, que son las tres principales lenguas de traducción en Macao, y este mismo criterio lingüístico se aplica a la escritura de los trabajos de investigación. El Instituto Politécnico de Macao se fundó en 1905, es una entidad pública dedicada a la formación de los traductores entre el chino y el portugués. Los cursos de traducción se limitan a las lenguas china, portuguesa e inglesa. En 2000 se dio inicio al programa de traducción 
de chino-inglés. Aunque las lenguas oficiales de Macao son el chino y el portugués, el inglés sigue siendo una lengua internacional y es una lengua popular de aprendizaje entre los jóvenes.

Según indica el director del centro de publicaciones de la Universidad de Macao, Guoqiang Wang ( $三$ 咸淯) en un artículo titulado El panorama general de la publicación de Macao en 2009 (Wang, 2010), durante los últimos diez años, la industria editorial se ha desarrollado rápidamente en Macao. Se han inaugurado varias librerías de lenguas extranjeras, han tenido lugar varias exposiciones de libros, el Gobierno de Macao también ha programado un presupuesto de libros destinado a entidades educativas etc., habiéndose publicado 400 libros hasta 2009, en sólo una década. En cuanto al contenido de los libros, las ciencias sociales ocupan el primer lugar, seguidos por el arte; la lengua y la literatura ocupan los últimos.

Si observamos la cantidad de los libros en chino sobre España, la lengua española y la traducción de la literatura española, la Biblioteca Central de Macao y las bibliotecas asociadas tienen una gran variedad de libros. Si bien estos libros catalogados son publicados mayoritariamente en Taiwán y en China, siendo pocos los publicados en Hong Kong o $\mathrm{Macao}^{2}$. Consideramos que es a consecuencia de que el español no es la lengua principal de comunicación o de didáctica y se utiliza poco. Por otro lado, hemos visto el aspecto especial de que la gran cantidad de este tipo de libros catalogados en el sistema bibliotecario de Macao aparece a partir del 2000, siendo desde entonces los textos relacionados con el español y España cada vez más apreciados en los últimos años.

Así pues, en el mercado del chino, la publicación de la traducción de las obras españolas se centra en China y en Taiwán, mientras Hong Kong y Macao son casos similares por la influencia histórica y las políticas de privilegiar solo el inglés entre las lenguas extranjeras. Durante los últimos años hay cada vez más traducciones de las novelas españolas contemporáneas en el mercado taiwanés, a la par que algunas de estas traducciones se encuentran en la lista de las mejores ventas ${ }^{3}$. En las librerías chinas pueden encontrarse versiones en chino simplificado de traducciones realizadas previamente por traductores de Taiwán en chino tradicional, lo que demuestra la calidad de la publicación taiwanesa. En este sentido, la situación de competición entre China y Taiwán se dirige hacia un modelo cooperativo. Los hechos generales de la publicación de textos españoles en el mundo chino dan pistas a nuestro trabajo y motivan a que estudiemos detenidamente el panorama de las publicaciones en China y en Taiwán, dos países de habla china que dedican más atención al español.

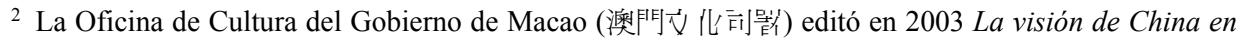

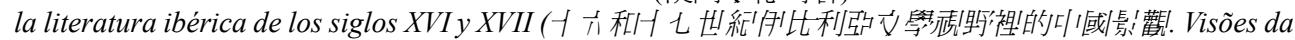
China na literatura ibérica dos séculos XVI E XVII. Antologia documental.) presentando las imágenes de China en los documentos portugueses y españoles, resultado de la publicación de la editorial Daxiang ( $九$ 身 ) de Zhengzhou (祊州) en China.

${ }^{3}$ En 2006 la traducción de la Sombra del viento en chino estuvo varios meses entre las diez más vendidas en la lista de la Librería Eslite de Taiwán y en 2009 las traducciones de Juego del ángel y La clave Gaudi también lograron el tercer y cuarto lugar de la literatura traducida durante un tiempo. 


\section{Factores del mecenazgo en las traducciones}

En este apartado, introducimos en primer lugar la propuesta del concepto de mecenazgo y sus principales componentes según Lefevere (1992/2004) con el fin de una aplicación clara a las industrias de publicaciones en China y en Taiwán. En los subapartados siguientes presentamos las situaciones actuales de las publicaciones de las obras literarias traducidas en China y en Taiwán durante los últimos diez años, tanto sus distintas culturas de publicaciones como los intercambios favorables resultado del mismo origen de sus lenguas oficiales.

\subsection{Influencias de factores del mecenazgo}

El factor del mecenazgo juega un papel importante en las tareas traductoras debido a que sus componentes pueden afectar a las traducciones a nivel global. Según Lefevere (1992/2004: 16), los tres elementos principales que forman el aspecto del mecenazgo en una traducción son la ideología, la economía y el estatus. El elemento ideológico puede influir en el formato o el tema, mientras que el factor económico aporta tranquilidad a los escritores y a las editoriales, ya que al tener respaldo económico disminuye la preocupación por la repercusión inmediata de la obra en el mercado, y el factor estatus, como los profesionales o los profesores, funciona como una garantía de calidad para los lectores.

En China, muchas veces podemos percibir que los tres elementos que componen el mecenazgo coexisten en el mismo momento a la hora de realizar una traducción. Una de las versiones inglesas de Sueño en el pabellón rojo (A Dream of Red Man-

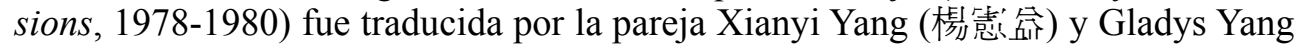
(頡つ号迷). Entonces, el gobierno chino intervino como editorial oficial y política principal de presentar a los lectores de habla anglosajona un contenido más fiel al original. Así pues, no es posible cualquier modificación como la adaptación a la cultura meta ni la amplificación o reducción, técnicas que van en contra de representar tal cual el texto original. El caso de la traducción de Sueño en el pabellón rojo por la pareja Yang muestra que el gobierno controla tanto el factor económico como el ideológico al mantener la línea editorial y decide cómo debe traducirse el texto original. Y es de destacar que en esta tarea traductora el aspecto político está, de hecho, unido al ideológico, porque la autoridad del gobierno chino no permite voces divergentes. En cuanto al estatus profesional que conlleva la fama de Yang como intelectual contemporáneo es, por supuesto, razón por la cual le han encargado esta tarea importante.

Nos gustaría destacar la influencia del factor económico en nuestro trabajo de estudiar y contrastar las estrategias de las editoriales en la actualidad. Si estudiamos la historia reciente de la traducción entre el chino y las lenguas extranjeras, observamos que hay bastantes casos que se explican por la influencia de la fuerza económica. Por ejemplo, la Editorial de Lenguas Extranjeras (外延社) de China fue fundada en 1952, todas sus publicaciones tienen como objetivo principal presentar originalmente las obras del chino a través de las traducciones. Según la página web de esta editorial en Internet, los títulos de la editorial abarcan temas políticos como las obras 
de los presidentes chinos, así como obras de política, economía, cultura, etc., lo que revela una relación estrecha con el gobierno chino. Siendo la primera editorial que tiene negocios con las editoriales extranjeras y la de mayor cantidad de intercambio de patentes, su papel de una sección dirigida por el gobierno y el apoyo económico de éste es la causa esencial del movimiento regular a lo largo del tiempo. Aunque hoy en día los factores económicos son más complicados de abarcar, en el caso de la Editorial de Lenguas Extranjeras, sin el apoyo económico del gobierno chino, es imposible realizar el proyecto de dar a conocer las obras chinas al mundo a través de las traducciones a más de cuarenta lenguas extranjeras.

\subsection{Tendencia de las publicaciones temáticas en China}

En China hoy en día hay bastantes publicaciones de las traducciones de obras españolas que son producto de las editoriales independientes, es decir, de compañías privadas, y este tipo de editoriales son las más comunes. Por ejemplo, la editorial

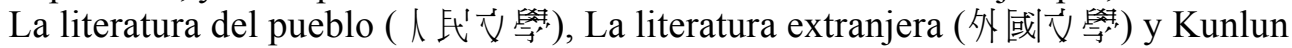
(些辇), entre otras. Entre las editoriales que pertenecen a entidades universitarias, destacan la Editorial de la formación e investigación de lenguas extranjeras (外詰敦

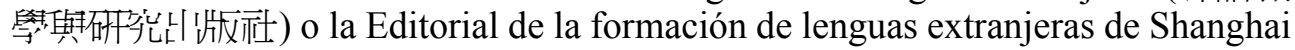

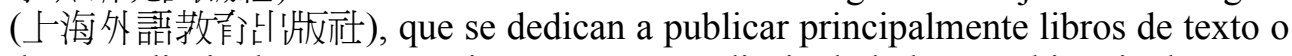
de aprendizaje de temas prácticos como aprendizaje de la lengua, historia de España, interpretación del español, etc., dejando a un lado las obras literarias ${ }^{4}$. La cantidad de traducciones de obras literarias no se ha incrementado hasta esta última década. Hemos visto que siempre hay algunos autores españoles que tienen varias traducciones al chino de sus obras: sin duda Miguel de Cervantes es un ejemplo clásico, del que se encuentran más de diez versiones de Don Quijote de la Mancha publicadas en chino; Leopoldo Alas también tienen unas cuantas obras traducidas al chino a partir de los años 90, si bien durante los últimos años las editoriales de China se han decantado por la política de publicar las traducciones de obras españolas por temas.

Hemos visto que hay series como "Las mejores novelas extranjeras del siglo

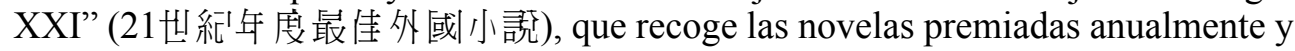
es fruto de una cooperación entre la Editorial de la literatura del pueblo y la Aso-

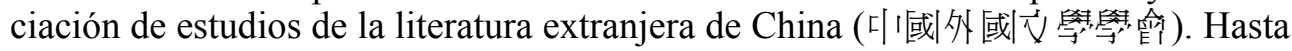
hoy en día, en total hay dos novelas de autores españoles: Mira si yo te querré (情

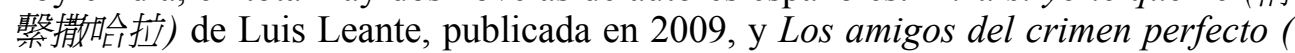
完美自出行少支) de Andrés Trapiello, publicada en 2005. Siendo el nombre de la serie Novelas Extranjeras, los sistemas lingüísticos de los textos originales incluyen también inglés, francés, alemán y ruso aparte del castellano. Respecto a las obras de

\footnotetext{
4 A finales de los años noventa había publicaciones de las historias de la literatura española, peruana, argentina y mexicana repectivamente, pero no tratan de las traducciones de las obras literarias, sino de la presentación de la literatura de dichos países.
} 
la lengua española, los autores premiados son tanto de España como de América. La autora mexicana Elena Poniatowska fue una de las autoras premiadas en 2002 por su obra La piel del cielo en el primer año que se celebró esta actividad. Por su parte, el autor peruano Alonso Cueto consiguió el premio del año 2006 por su obra La hora azul. De allí se observa un equilibrio de la literatura entre España y Latinoamérica en China, puesto que se respetan las obras de diferentes orígenes sin honrar meramente a autores europeos, que son los que disfrutan de mayor prestigio tradicionalmente.

Por otro lado, con el fin de celebrar el Año de España en China, en el año 2007 el Ministerio de Cultura español en colaboración con dos editoriales chinas publicó una serie de obras dedicadas principalmente a los autores españoles del siglo XX.

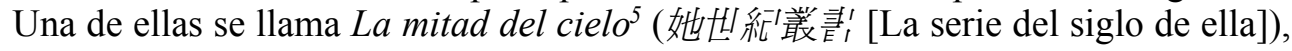
publicada por la misma editorial, La literatura del pueblo, durante 2007, 2008 y 2009, compilada en doce volúmenes de traducción en chino de las novelas de las doce autoras españolas, a saber: Irse de casa de Carmen Martín Gaite, Recóndita armonía de Marina Mayoral, El lado frío de la almohada de Belén Gopegui, El hueco de tu cuerpo de Paula Izquierdo, Una palabra tuya de Elvira Lindo, Nada de Carmen Laforet, El silencio de las sirenas de Adelaida García Morales, El año de gracia de Cristina Fernández Cubas, Un calor tan cercano de Maruja Torres, La canción de Dorotea de Rosa Regés, La voz dormida de Dulce Chacón y El mismo mar de todos los veranos de Esther Tusquets. El valor de esta serie es peculiar porque ha sido la primera vez que se ha publicado una presentación tan numerosa de escritoras españolas y en doce volúmenes, lo que atrae poderosamente la atención de los lectores.

La otra serie de traducción de obras españolas peninsulares se titula La serie de la literatura ibérica (体上利卧式或), fruto de una subvención del Ministerio de Cultura español y el apoyo y la colaboración entre la Embajada de España en China

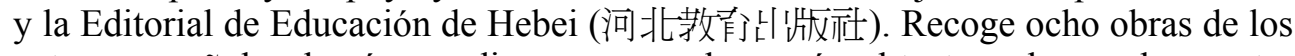
autores españoles de géneros diversos como la poesía, el teatro y la novela, y entre las ocho traducciones hay seis que son de tipo antológico. En comparación con la serie de La mitd del cielo, los autores y las obras de La serie de la literatura ibérica son relativamente famosas a nivel internacional: Antología de poesía de Juan Ramón Jiménez, Antología de las obras teatrales de Federico García Lorca, Antología de peosía de Antonio Machado, Sangre y arena de Vicente Blasco Ibáñez, Al morir don Quijote y Las vidas de Miguel de Cervantes de Andrés Trapiello, Comedias Escogidas de Lope de Vega y Sonrie China, Antología de poesía de Rafael

${ }^{5}$ El título de la serie refleja las palabras de Mao, cuando él pretendió expandir los derechos y dignidad femeninos para que las mujeres pudieran participar en todo tipo de actividades sociales como los varones,

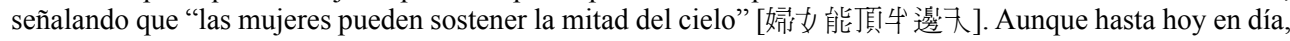
en la sociedad china se ve que es poco plausible que las mujeres lleguen a obtener la igualdad en todos los sentidos. Esta expresión ha dado nombre a un libro publicado en EEUU en 2010: Half the Sky: Turning Oppression into Opportunity for Women Worldwide, por Random House Inc., cuyo contenido está basado en la igualdad de los dos sexos. El uso de la expresión "las mujeres pueden sostener la mitad del cielo" se va haciendo cada vez más universal. 
Alberti. A través tanto de La serie de la literatura ibérica como de La mitad del cielo hemos visto que hay pocos títulos repetidos con las traducciones publicadas anteriormente ${ }^{6}$, por lo que consideramos que estas selecciones ofrecen asimismo una oportunidad de conocer mejor al mundo literario hispánico y coinciden con el espíritu del gobierno español de aprovechar el Año de España en China para presentar mayores conocimientos al pueblo chino. Además, la publicación temática que introduce una cantidad mayor de obras confirma el valor y la importancia cada vez mayor que se da a la literatura española en China;la cooperación entre las editoriales con las asociaciones literarias o con entidades gubernamentales es uno de los factores del mecenazgo que contribuye a convertir los proyectos de publicación en realidad, sobre todo, gracias a la subvención económica del Ministerio de Cultura español, cuyo apoyo es esencial a la hora de realizar todos estos proyectos de publicación.

\subsection{Publicaciones por autores en Taiwán}

El mercado taiwanés de libros no comparte las mismas estrategias mercantiles que las de China. Durante esta última década, las publicaciones de las traducciones de obras literarias en Taiwán son planes independientes sin ninguna subvención oficial del gobierno español ${ }^{7}$. Las traducciones de obras españolas son publicadas prin-

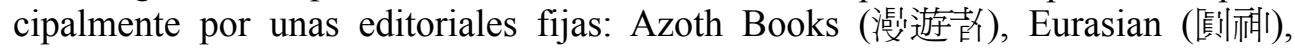
Crown ( dades españolas oficiales con las que cooperan para las publicaciones del género novelístico español. Por un lado, las editoriales tienen bastante libertad en la selección de los textos originales, y por otro, las editoriales se ven obligadas a considerar los factores económicos en sus publicaciones.

Podemos decir que Azoth Books es la editorial agente de Arturo Pérez Reverte en Taiwán. Además de la calidad de académico de la RAE y como escritor experimentado por su profesión periodista, la popularidad de Pérez Reverte en España y en más de treinta países de ultramar favoreció que en 2007 Azoth Books firmara el derecho de traducción de las siete novelas de Pérez Reverte al chino no simplificado: El maestro de esgrima (1988), La tabla de Flandes (1990), El club Dumas (1993), La piel del

${ }^{6}$ Hay unas traducciones que se publicaron hace tiempo que coinciden con los temas de La serie de la

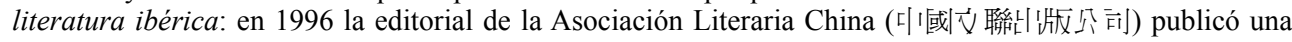
antología de Obras teatrales de García Lorca, traducida por Wen Chen, mientras que en 1997 la Editorial Lijiang (洌汇) publicó Arias Tristes de Juan Ramón Jiménez, traducida por Zhenjian Zhao. Consideramos que las últimas traducciones son renovadas tanto en la selección de las piezas como en el contendio de sus traducciones.

${ }^{7}$ Hay que destacar que durante los años 80, el Departamento de Lengua y Literatura Hispanoamericana de la Universidad Católica Fujen de Taiwán obtuvo una subvención del Ministerio de Cultura español. Así, la primera serie de traducción de teatros contemporáneas españoleas y debido a su formato bilingüe ha tenido un gran valor tanto para los expertos teatrales como para los que estudian el castellano. Esta serie de unos diez volúmenes de traducciones fue publicada por la Editorial Central Books de Taiwán y aunque desde hace tiempo la editorial ha dejado de publicarla, podemos encontrar los ejemplares en las bibliotecas de varias universidades taiwanesas. 
tambor (1995), La carta esférica (2000), La Reina del Sur (2002) y El pintor de batallas (2006). Aunque hasta ahora aún faltan las traducciones de El maestro de esgrima y La piel del tambor, la rapidez de la presentación de cinco novelas en cuatro años revela su ambición y confianza en la aceptación general de los lectores taiwaneses. Asimismo, la publicación continuada marca un ejemplo exitoso de la importación de la literatura contemporánea española. Antes de la traducción de Azoth Books, hay dos

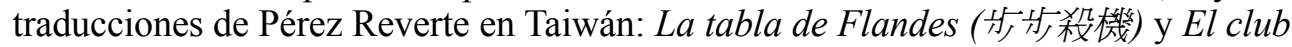
Dumas (大什監候樂都), publicadas en 1995 y 2001 respectivamente por las

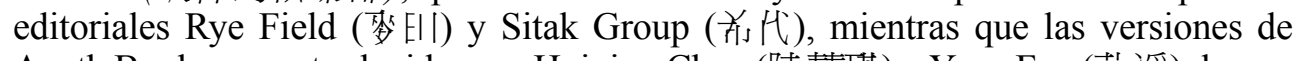
Azoth Books son retraducidas por Huiying Chen (捄詵贲) y Yuan Fan (范湲), lo que favorece también una calidad progresiva de las traducciones.

La editorial Eurasian publica cierta variedad de versiones en chino de las novelas contemporáneas de autores españoles y es considerada la editorial de mayor cantidad de publicación de dichos libros hoy en día en Taiwán. Sin embargo, no existe una categoría de literatura contemporánea española, sino que se agrupa junto con literaturas de otras lenguas con el nombre Literatura contemporánea. Entre 2004 y 2006, Eurasian publicó tres obras traducidas de Juan José Millás: la primera es una antología de las

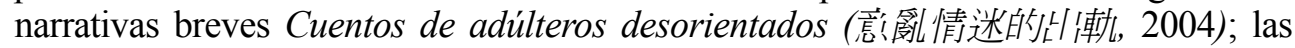

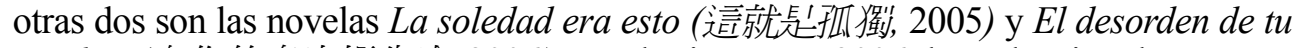

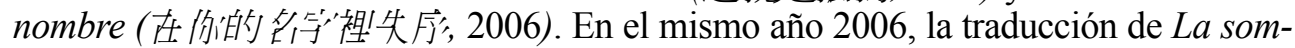
bra del viento (2001) en chino, 歌-影 (2006) ha llamado bastante la atención, ya que esta novela ocupó por un largo tiempo las listas de las mejores ventas en las librerías de Taiwán. Unos años más tarde, se publicó la traducción de El juego del ángel (2008), ح 伖遊笁 (2009), también del mismo autor, Carlos Ruiz Zafón. A partir de 2006, se ve con más claridad que Eurasian impulsó su proyecto de dar a conocer novelas españolas en chino tradicional. Además de las novelas mencionadas de Millás y Zafón, las

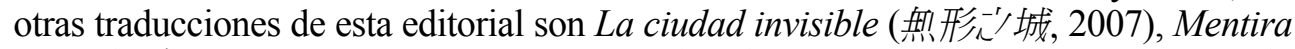

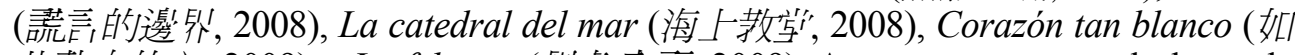

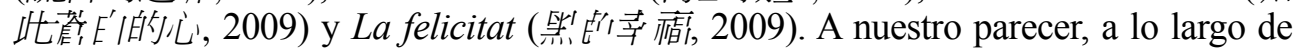
todos estos años, la publicación de estos títulos ha garantizado que se puede formar una categoría independiente. Sin embargo, parece que la editorial todavía tiene falta de confianza y está evaluando el mercado de la novela española en Taiwán.

Merece la pena destacar que la editorial Crown publicó en estos últimos años cinco novelas de autores españoles: La pell freda ('水椧肌管, 2008), La sonrisa

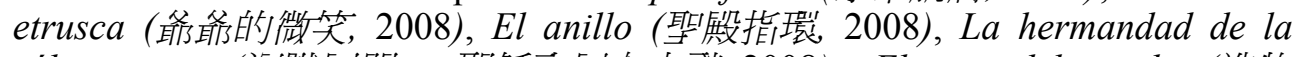

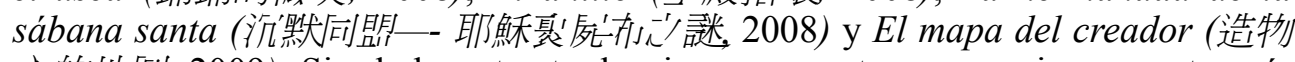

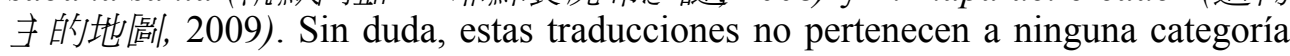
literaria fija, como ha ocurrrido en otras editoriales, y los autores de las cinco novelas también son diversos y es de esperar que Crown siga con su política de traducir más obras españolas. Sin embargo, la publicación de otras editoriales, como Rye Field (荅F'l) o China Times (時舒), no es tan constante y la cantidad de las novelas traducidas tampoco es tan competitiva como la de las editoriales que hemos estudiado. Tal como hemos mencionado, en 1995 Rye Field publicó la traducción de $L a$ tabla de Flandes y la última traducción que ha publicado la misma editorial es 㖵佮

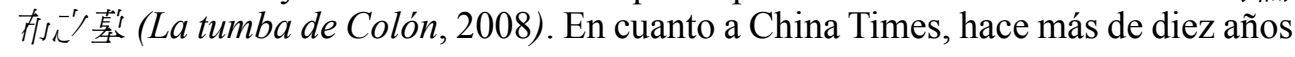


publicó La familia de Pascual Duarte (杜考特笑族 1992) y estos años tiene

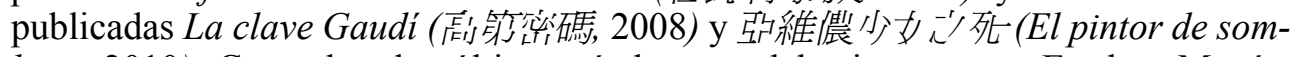
bras, 2010). Como los dos ultimos títulos son del mismo autor, Esteban Martín, hemos considerado una posible publicación del mismo autor en el futuro.

Tal como hemos visto, pueden identificarse dos tendencias de publicación de las obras españolas en Taiwán durante los últimos diez años. En primer lugar, la literatura española se mezcla en la categoría de literatura con otros países extranjeros con títulos como Literatura contemporánea. Consideramos que es el primer paso para introducir literatura extranjera ante la inseguridad de la venta en el mercado. En segundo lugar, como hemos indicado al principio, de momento existe un fenómeno de publicaciones de las novelas contemporáneas en Taiwán del mismo autor. En este sentido, la publicación de Azoth Books de las traducciones de siete novelas de Pérez Reverte abre otro camino a la presentación de obras españolas. Aunque debido a factores políticos, las editoriales taiwanesas no consiguen las subvenciones gubernamentales españolas como China para poder publicar series de traducciones de autores españoles, sin considerar demasiado las posibles consecuencias del interés mercantil, en Taiwán se encuentra otra cultura diferente de las editoriales al aprovechar la mayor libertad informática de acudir a los premios literarios de ultramar e informaciones internacionales para introducir autores y obras de diferentes estilos.

\subsection{Factores económicos que contribuyen a las colaboraciones}

El chino simplificado usado en China y el no simplificado o tradicional aplicado en Taiwán son, de hecho, la misma lengua del chino mandarín. Aunque es inevitable que a lo largo del tiempo y también debido al factor geográfico haya matices entre ambos, bien de pronunciación, terminología, gramática, etc. A pesar de los diferentes sistemas de escritura, los dos sistemas del chino pertenecen efectivamente a la misma lengua; podemos decir, con matices, que es la misma situación del español peninsular en relación con el de América. Aprovechándose de este fenómeno lingüístico del mismo origen, existen también diferentes oportunidades y necesidades de traducción entre sí, con tan sólo ver que los diccionarios de los dos sistema del chino son productos bajo esta situación y tienen su valor práctico.

Durante los últimos diez años se han publicado bastantes ejemplares de traducciones de las novelas españolas al chino. Sin duda, hay traducciones que sólo se encuentran en China o en Taiwán, según la selección realizada por las editoriales. Por otro lado, hemos visto que hay novelas traducidas por taiwaneses publicadas en China tras su publicación en el mercado taiwanés, así como novelas del mismo título traducidas tanto por traductores chinos como taiwaneses que se venden en los dos países indistintamente. En cuanto a las traducciones realizadas por los traductores chinos exportadas con patente a Taiwán, los ejemplos son escasos. Estas novelas traducidas por expertos chinos y luego vendidas por una editorial taiwanesa se encuentran en los años noventa, cuando en Taiwán todavía no había prosperado la industria de traducción literaria hispanoamericana. Los ejemplos representativos son

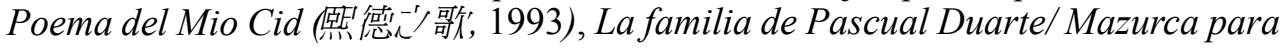




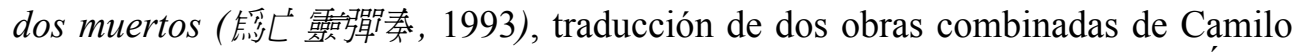
José Cela; una traducción de la obra del escritor latinoamericano Miguel Ángel Asturias: 粐 ^(Hombres de maiz, 1994), siendo las tres publicaciones de la editorial 桂完 (Laurel). Asimismo, hemos detectado que en 2005 hay tres volúmenes de la serie Ami por el autor chileno-venezolano Enrique Barrios traducidos por el profesor chino Deming Zhao (越德門), publicados en Taiwán. Por el momento, en Taiwán no se encuentran más traducciones de novelas españolas retraducidas.

Los casos más frecuentes constatan que hay bastantes novelas contemporáneas de escritores españoles que han sido traducidas al chino no simplificado en Taiwán y después las editoriales chinas han comprado los derechos para volver a publicarlas en China. Entre estas novelas destacan las siguientes: La sonrisa etrusca (1985) de José Luis Sampedro, La tabla de Flandes (1990) y El club Dumas (1993) de Arturo Pérez Reverte, La sombra del viento (2001) de Carlos Ruiz Zafón, La pell freda (2002) de Albert Sánchez Piñol, La tumba de Colón (2006) de Miguel Ruiz Montañez y La catedral del mar (2006) de Ildefonso Falcones, etc. Asimismo, nos hemos fijado en que durante el proceso traslativo entre la versión del chino simplificado y el no simplificado, los principales elementos alternados son las escrituras y el formato de maquetación del vertical en Taiwán al horizontal en China, cambios de uso de expresiones debido a la costumbre lingüística, así como modificaciones del título de la versión del chino simplificado al 海_一大改 Taiwán: 海_一大教斯 [La catedral del mar], y 徐坐 [la piel fría] de versión de China vs. 冰冷肌韩 [la piel fría] de Taiwán debido a la variación lingüística y geográfica. Debido a las características favorables entre el chino en China y en Taiwán, todas estas tareas de retraducción para acomodar a los lectores de China convierten el proceso de publicación de las traducciones en un proceso mucho más económico. No obstante, también es natural que exista el mismo título traducido por diferentes traductores y publicado en China y en Taiwán respectivamente como La ciutat invisible (2005) de Emili Rosales o El mapa del creador (2006) de Emilio Calderón.

Este fenómeno de la compra de derechos de las traducciones taiwanesas es peculiar frente a la ideología tradicional de que China es el origen y el patrón en todos los aspectos relacionados con la cultura china. Si comparamos la población de China y Taiwán y los expertos que se dedican a la traducción en los dos territorios, el número de personas dedicadas a la traducción del castellano en China debería superar varias veces a la de Taiwán. Sin embargo, el hecho de que en Taiwán haya más traducciones de novelas españolas durantes estos últimos años muestra el aumento de la apreciación de la literatura peninsular en Taiwán y demuestra la tendencia y la preferencia de la selección de las novedades en Taiwán ${ }^{8}$.

\footnotetext{
${ }^{8}$ Esta tendencia coincide con las situaciones generales de los intercambios de patentes entre China y Taiwán, ya que "las obras populares en China y publicadas en Taiwán son las de la cultura popular, mientras las exportadas de China a Taiwán son obras de literatura seria” (Kato(ed.) 2004: 77), lo que quiere decir que la selección diferente en cuanto a los temas publicados: las editoriales taiwanesas se decantan por los títulos recientes, mientras que las chinas toman una política contraria.
} 


\section{Conclusiones}

En Asia, las publicaciones de los temas relacionados con España o el español se centran en China y en Taiwán. Aunque Hong Kong y Macao no están nada menos internacionalizados dada su historia de la colonización por Inglaterra y Portugal, el español no llega a ser una conocida lengua práctica, contando con más actividades de intercambios en inglés debido a su importancia a nivel internacional. Dicha situación a consecuencia de la globalización afecta directamente a la formación escolar y a las políticas de las editoriales en Hong Kong y en Macao. Por tanto, actualmente en el mundo de habla china contamos con China y Taiwán como los dos países en los que hay un equilibrio relativo del desarrollo lingüístico y se encuentran las publicaciones de temas relacionados con el castellano.

Observamos que los sistemas de mecenazgo de las publicaciones en China y en Taiwán influyen directamente en las estrategias de las editoriales y forman diferentes culturas de la publicación de las novelas españolas durante esta última década. En China, la cooperación de la editorial con las asociaciones literarias o con el gobierno español favorecen la publicación de una cantidad mayor de obras por temas; las aportaciones de los mecenas en cuanto a su fuerza económica garantiza el cumplimiento de estos proyectos temáticos de colaboraciones entre varias entidades. Frente a las editoriales de Taiwán, con presupuestos independientes, lo más seguro es una estrategia de publicación escalonada y junto con literaturas de otras lenguas para minimizar el riesgo mercantil. Consideramos que el fenómeno de publicación contínua por autores como Millás, Zafón y Pérez Reverte es el resultado positvo de las repercusiones de su última obra. Las principales diferencias de los modelos editoriales en China y en Taiwán no va a cambiar fácilmente a no ser que haya cambios en los factores de mecenazgo, que son la clave de las estrategias de las editoriales.

Como consecuencia de los distintos componentes de los mecenas en las dos culturas chinas, hemos vistos que la selección de los materiales de las traducciones también marca una divergencia obvia. Las obras traducidas en China son relativamente clásicas, por ejemplo, La serie de la literatura ibérica, aunque también cuentan con obras más recientes del siglo XXI como Las mejores novelas extranjeras del siglo XXI y La mitad del cielo, pero no se centran en las novedades, sino en los temas. Por otro lado, las novelas publicadas en Taiwán son de las últimas generaciones literarias. Como las editoriales taiwanesas no cuentan con los mecenas gubernamentales ni de Taiwán ni de España, el sincronismo con la publicación internacional es la vía más segura de garantizar su éxito mercatil, los autores escogidos son exitosos y sus obras han sido traducidas previamente en varios países no hispanoparlantes.

Las diferencias políticas y culturales de las publicaciones de las traducciones de novelas durantes esta última década favorecen un panorama próspero de la literatura española en el mundo chino. Además, la divergencia estratégia temática favorece la colaboración entre China y Taiwán y gracias a ella los intercambios de las obras traducidas amplian los campos de los temas introducidos en un solo país. Por el momento, hemos visto que China ha comprado varias patentes de las novelas traducidas en Taiwán y las ha publicado de nuevo en chino simplificado, revelando su 
apreciación en cuanto a las publicaciones de Taiwán, de lo que puede inferirse un mayor grado de aceptación de China hacia otro sistema político.

\section{Referencias bibliográficas}

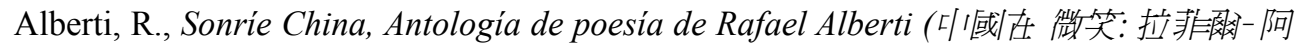

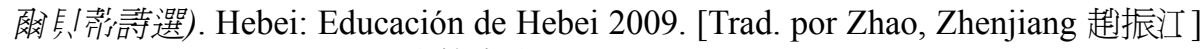

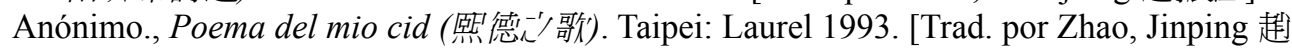
솓ㄱ. 기

Asturias, M., Hombres de maiz (马 米 ^). Taipei: Laurel 1994. [Trad. por Liu, Xiliang y Sun,

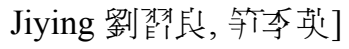

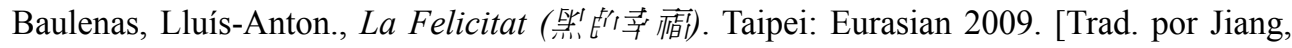
Huizhen 汇琴其!

Blasco Ibáñez, V., Sangre y arena (的染声-1秋). Hebei: Educación de Hebei 2008. [Trad. por Lin, Guang 林㕱]

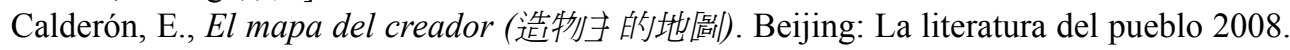

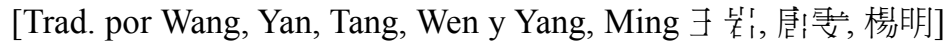

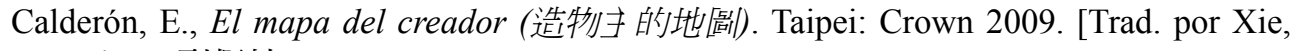
Peiwen 誎俯她]

Cao, Xueqing y Gao, E., A Dream of Red Mansions. Beijing, Lenguas Extranjeras 1978.

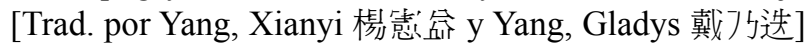

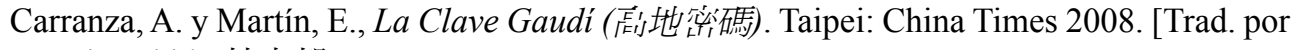
Lin, Zhidu 林志郳]

Chacón, D., La voz dormida (汽堙的臂芦I). Beijing: La literatura del pueblo 2007. [Trad. por $\mathrm{Xu}$, Lei 徐整计

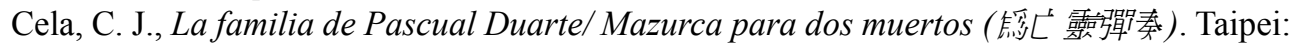
Laurel 1993. [Trad. por Li, Deming etc. 㞭德門突]

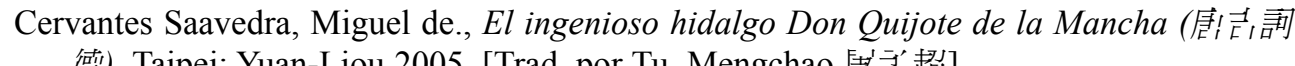

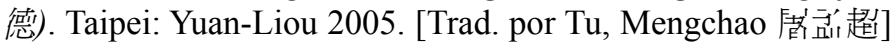

Cueto, A., La hora azul (譬到性都). Beijing: La literatura del pueblo 2007. [Trad. por Liu, Jingsheng 贸肺胼]

Falcones, I., La catedral del Mar (浴上新斯). Taipei: Eurasian 2008. [Trad. por Fan,Yuan 范湲]

Fernández Cubas, C., El año de gracia (二墈,卢年). Beijing: La literatura del pueblo 2007. [Trad. por Zhu, Kai 未凱]

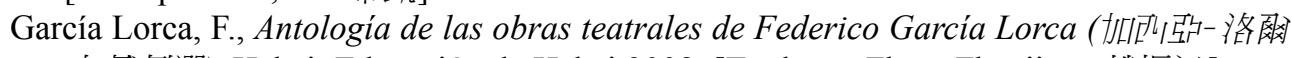

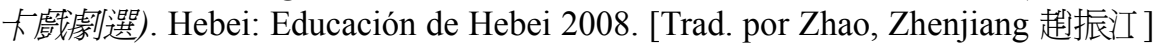

García Morales, A., El silencio de las sirenas (莱三的沿壆). Beijing: La literatura del pueblo 2007. [Trad. por Zheng, Shujiu 新琵打]

Gopegui, B., El lado frío de la almohada (清冷梑畑). Beijing: La literatura del pueblo 2008. [Trad. por Cui, Yan 管'燕]

Grandes, A., Las edades de Lulu (震震). Taipei: Eurasian 2003. [Trad. por Fan, Yuan 范湲]

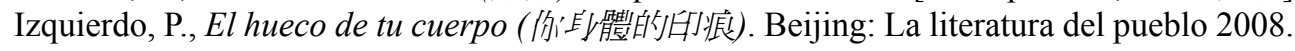
[Trad. por Zhan, Ling 虞识全] 


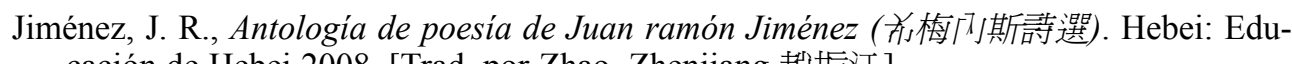
cación de Hebei 2008. [Trad. por Zhao, Zhenjiang 越掁:]

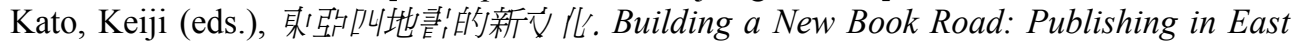
Asia. Taipei: Net and Books 2004.

$\mathrm{Ku}$, Menghsuan., «Tendencias del mercado taiwanés en la traducción al chino de novelas contemporáneas en español», Hermeneus 12 (2010), 183- 204.

Laforet, C., Nada (年胼). Beijing: La literatura del pueblo 2007. [Trad. por Bian,

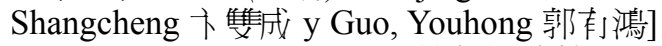

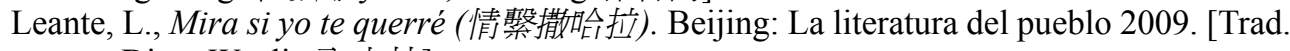
por Ding, Wenlin $\neg \Downarrow$ 林]

Lefevere, A., Translation, rewriting and the Manipulation of Literary Fame. Shanghai: Educación de lengua extranjera 1992/ 2004.

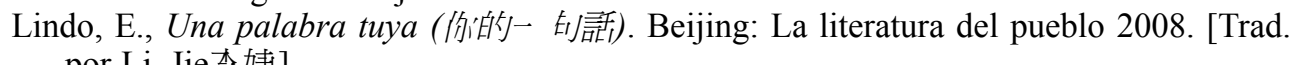
por Li, Jie夺婧]

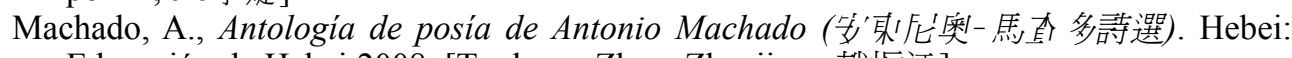
Educación de Hebei 2008. [Trad. por Zhao, Zhenjiang 越拾?]

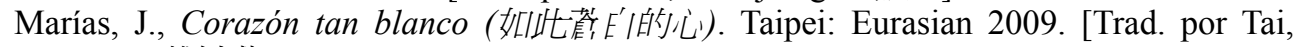
Yufen 嗔每粦势 ]

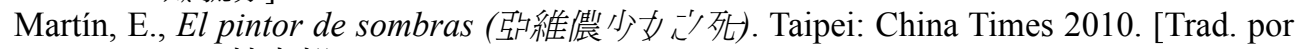
Lin, Zhidu 林志㺃]

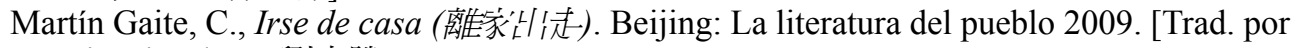
Liu, Jingsheng 㡂脚胯]

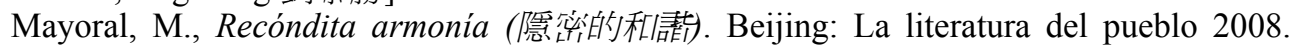
[Trad. por Yang, Ling 樹-70年]

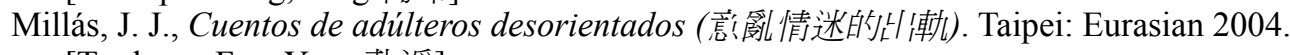
[Trad. por Fan, Yuan 范湲]

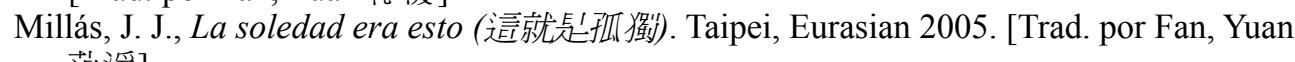
范湲]

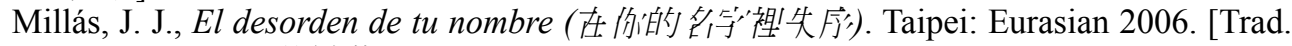

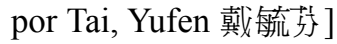

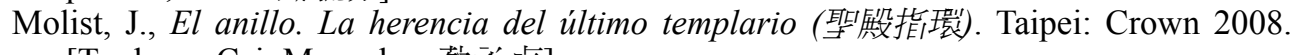
[Trad. por Cai, Mengzhen 㢣言吉!]

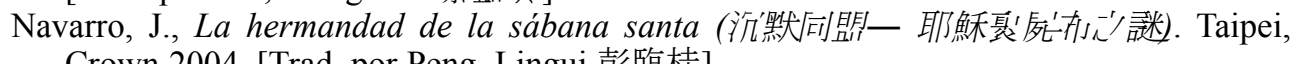
Crown 2004. [Trad. por Peng, Lingui 彭臨桂]

Nicholas, K., Sheryl, W., Half the Sky: Turning Oppression into Opportunity for Women Worldwide. New York: Random House 2010.

Oficina de Cultura del gobierno de Macao, La. (ed.), La visión de China en la literatura ibé-

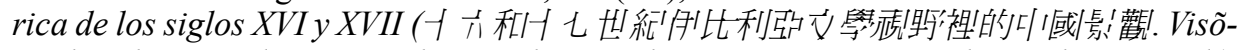
es da China na literatura ibérica dos séculos XVI E XVII. Antologia documental.). Zhengzhou: Daxiang 2003.

Pérez-Reverte, A., El maestro de esgrima. Madrid: Alfaguara 1988.

Pérez-Reverte, A., La tabla de Flandes. Madrid: Alfaguara 1990.

Pérez-Reverte, A., El club Dumas. Madrid: Alfaguara 1993.

Pérez-Reverte, A., La piel del tambor. Madrid: Alfaguara 1995a.

Pérez-Reverte, A., La tabla de Flandes (将非殺楼). Taipei: Rye Field 1995b. [Trad. por

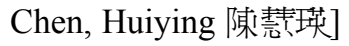

Pérez-Reverte, A., La carta esférica. Madrid: Alfaguara 2000.

Pérez-Reverte, A., El club Dumas (大作孯信樂都). Taipei: Sitak 2001. [Trad. por Chen,

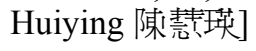


Pérez-Reverte, A., La Reina del Sur. Madrid: Alfaguara 2002.

Pérez-Reverte, A., El club Dumas (大作監焦樂都). Chongqing: Chongqing 2005. [Trad. por Chen, Huiying 陠蒙装了

Pérez-Reverte, A., El pintor de batallas. Madrid: Alfaguara 2006a.

Pérez-Reverte, A., La tbala de Flandes (垡坋殺涉). Chongqing: Chongqing 2006b. [Trad. por Wu, Jiaqi 战秉綺]

Pérez-Reverte, A., La tabla de Flandes (洼剧德訏棋艘). Taipei: Azoth 2007. [Trad. por

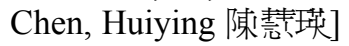

Pérez-Reverte, A., El pintor de batallas (践结录!射). Taipei: Azoth 2008a. [Trad. por Zhang, Wenyuan 張灵媛]

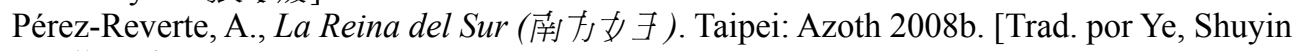
禁淑信]

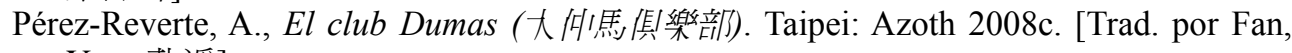
Yuan 范湲]

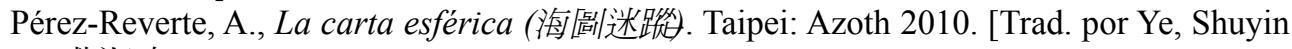
禁淑信]

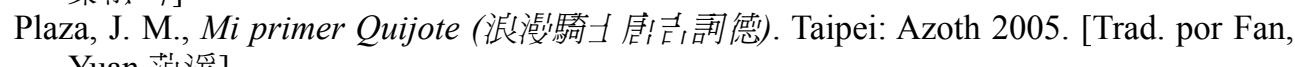
Yuan 范湲]

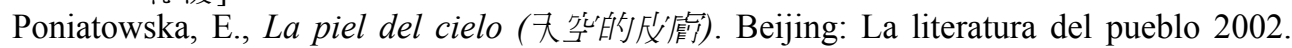

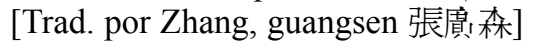

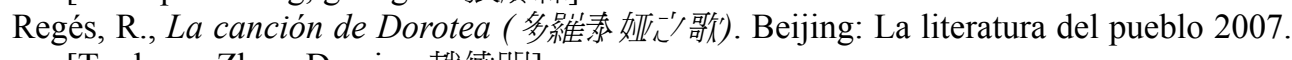
[Trad. por Zhao, Deming 越德門]

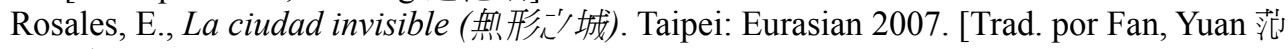
湲]

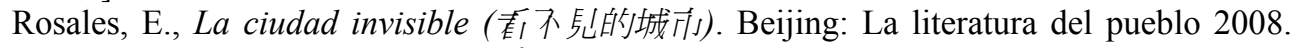
[Trad. por Yin, Chendong 壮望甫]

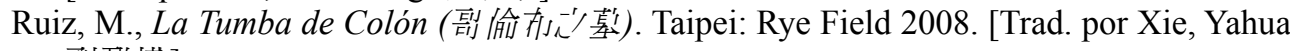
尌产恶桯]

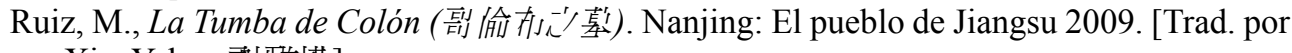

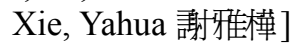

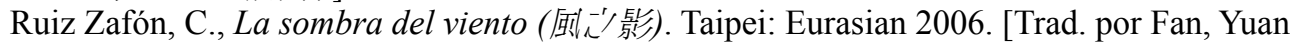
范湲]

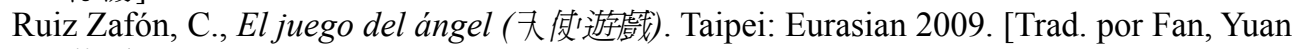
范湲]

Sampedro, J. L., La Sonrisa Etrusca (武武的些冬). Taipei: Crown 2008. [Trad. por Lin, Liren 林寸 [ []

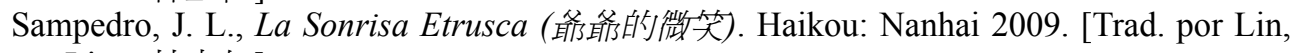
Liren 林寸 [臣]

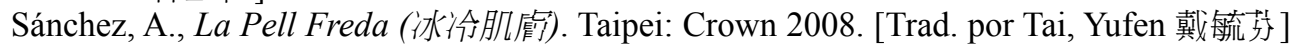

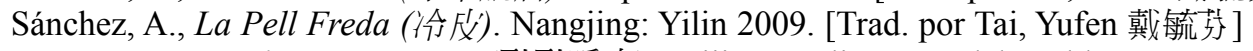

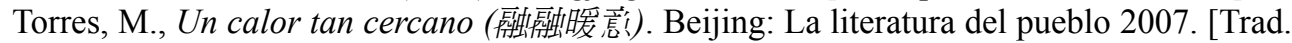

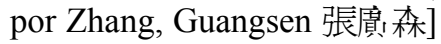

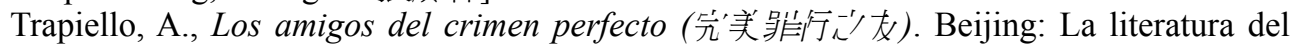
pueblo 2005. [Trad. por Li, Deming 㞭德胢]

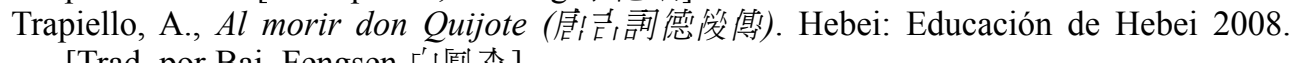
[Trad. por Bai, Fengsen EI㦛杂]

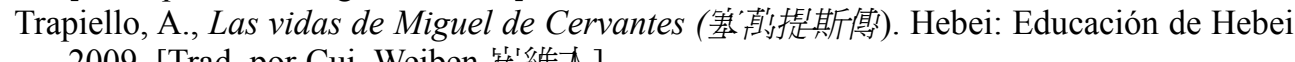
2009. [Trad. por Cui, Weiben 管紹本] 


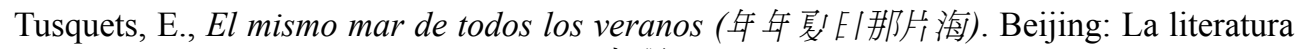
del pueblo 2007. [Trad. por Bu, Shan 卜判]

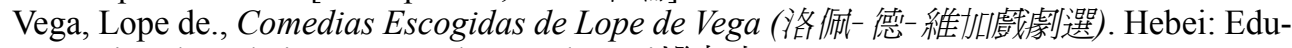
cación de Hebei 2008. [Trad. Hu, Zhencai胡斯\}]

Wang, Guoqiang 三 域䮁. «El panorama general de la publicación de Macao en 2009», Información mensual de las nuevas publicaciones en Taiwán 133 (2010), 95-96.

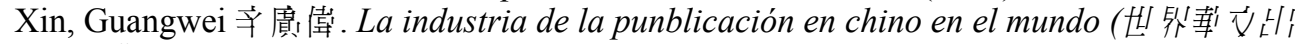
特芦). Taipei: Yuan-Liou 2010. 